\title{
Once-daily glycopyrronium bromide, a long-acting muscarinic antagonist, for chronic obstructive pulmonary disease: a systematic review of clinical benefit
}

\author{
This article was published in the following Dove Press journal: \\ International Journal of COPD \\ 25 September 2012 \\ Number of times this article has been viewed
}

\author{
Charlotte Suppli Ulrik \\ Department of Pulmonary Medicine, \\ Hvidovre Hospital and University \\ of Copenhagen, Copenhagen, \\ Denmark
}

Background: Long-acting bronchodilators are central in the pharmacological management of patients with chronic obstructive pulmonary disease (COPD). The aim of this systematic review is to provide an overview of the studies evaluating the safety and clinical efficacy of inhaled glycopyrronium bromide, a novel long-acting muscarinic antagonist, in patients with COPD. Methods: This study was performed as a systematic literature review.

Results: Inhaled glycopyrronium bromide seems to be a safe and well tolerated long-acting muscarinic antagonist with a fast onset of action. In patients suffering from moderate to severe COPD, glycopyrronium bromide has clinically important effects on level of forced expiratory volume in one second, use of relief medication, percentage of days with no use of rescue medication, daytime dyspnea scores, and probably also on health status. Furthermore, in this group of patients, glycopyrronium bromide has beneficial effects on dynamic hyperinflation and exercise tolerance. Glycopyrronium bromide has been shown to reduce the rate of exacerbations in patients with moderate to severe COPD, but long-term controlled trials with exacerbation rate as the primary outcome variable have not been published yet.

Conclusion: Once-daily inhaled glycopyrronium bromide has characteristics important for use in COPD, including a fast onset of action, sustained 24-hour bronchodilatation, and improvement in exercise tolerance, and therefore appears to have the potential for a significant role in the future management of COPD.

Keywords: chronic obstructive pulmonary disease, glycopyrronium bromide, long-acting bronchodilators

\section{Introduction}

The Global Initiative for Chronic Obstructive Pulmonary Disease (GOLD strategy document) recommends the use of long-acting bronchodilators as first-line maintenance therapy for patients with moderate to severe chronic obstructive pulmonary disease (COPD). ${ }^{1,2}$ Clinical studies of patients with COPD show that long-acting bronchodilators have a positive impact on prevention and control of symptoms, severity and rate of exacerbations, quality of life, and exercise capacity. ${ }^{1,3,4}$

Dyspnea is the hallmark symptom of COPD, and dyspnea is the main reason for patients suffering from COPD seeking medical attention. ${ }^{1}$ Dyspnea is probably also the most important cause of COPD-related anxiety and disability. ${ }^{1}$ Long-acting bronchodilators reduce lung volumes by a reduction in air trapping and an improvement in emptying of the lungs, which leads to an improvement in dyspnea and
Correspondence: Charlotte Suppli Ulrik Department of Pulmonary Medicine, 253 Hvidovre Hospital, DK-2650 Hvidovre, Copenhagen, Denmark Email csulrik@dadlnet.dk 
exercise capacity. ${ }^{1,3,5}$ Long-acting bronchodilators, including $\beta_{2}$-agonists and antimuscarinic agents, are therefore key elements in the symptomatic management of COPD.

Long-acting anticholinergic agents may be the most effective class of bronchodilators for COPD, ${ }^{1,2,6,7}$ and although tiotropium bromide is the only long-acting anticholinergic bronchodilator marketed for COPD, several others are in various stages of development, including glycopyrronium bromide. Glycopyrronium bromide has been used for years, administered as injections or tablets, as an adjunct in peptic ulcer disorders, to diminish secretions and block cardiac vagal reflexes before surgery, and has now been developed as an inhaled agent for the treatment of COPD. This short review provides an overview of the available clinical studies evaluating the safety and efficacy of inhaled glycopyrronium bromide in patients with moderate to severe COPD.

\section{Materials and methods}

A series of systematic searches were carried out and last updated in August 2012, using the database PubMed. The strategy was intended to be broad in order to maximize the capture of citations for peer-reviewed publications relevant to glycopyrronium bromide and COPD. The PubMed searches were carried out using the following algorithm of MeSH terms: glycopyrronium bromide, NVA237, long-acting antimuscarinic agents, indacaterol, salmeterol, formoterol, tiotropium bromide, aclidinium bromide, longacting bronchodilators, and COPD, and the searches were repeated with these terms in combination with forced expiratory volume in one second $\left(\mathrm{FEV}_{1}\right)$, hyperinflation, exercise capacity, dyspnea, health status, exacerbations, and adverse effects. The citation pool was further supplemented from manual assessment of the reference lists in identified reviews and clinical studies of aspects related to long-acting bronchodilators and COPD and from other publications identified as being relevant for further review. All identified randomized studies published in peer-reviewed journals of glycopyrronium bromide for the treatment of COPD are included in the present review.

\section{Results}

\section{Activity profile and safety} of glycopyrronium bromide

Glycopyrronium bromide (NVA237) is a synthetic quaternary ammonium compound acting as a competitive antagonist by binding to muscarinic receptors in bronchial smooth muscle, thereby inhibiting acetylcholine-induced bronchoconstriction.
Glycopyrronium bromide binds to all five subtypes of the muscarinic receptor $\left(M_{1}-M_{5}\right)$, of which the $M_{3}$ receptor located on airway smooth muscle is primarily involved in smooth muscle contraction. Blockade of $\mathrm{M}_{2}$ receptors attenuates the feedback inhibition of acetylcholine production, and thereby may reduce the bronchodilating effects of an antimuscarinic agent. Furthermore, blocking cardiac $\mathrm{M}_{2}$ receptors may result in an increase in heart rate. Therefore, the optimal antimuscarinic agent for use in COPD has high affinity for $M_{1}$ and $M_{3}$ receptors and low affinity for $\mathrm{M}_{2}$ receptors. Like tiotropium bromide, glycopyrronium bromide has higher selectivity for $\mathrm{M}_{3}$ receptors than for $\mathrm{M}_{2}$ receptors, and like both tiotropium bromide and aclidinium bromide, dissociates more slowly from the $\mathrm{M}_{3}$ receptor than it does from the $\mathrm{M}_{2}$ receptor. ${ }^{8,9}$ Therefore, glycopyrronium bromide provides bronchodilatation via $\mathrm{M}_{3}$ blockade long after its less desirable $M_{2}$ effects, such as an increased heart rate..$^{8-10}$

In vitro studies have indicated that glycopyrronium bromide may have a faster onset of action than tiotropium, and this has been confirmed in clinical studies. ${ }^{8,11}$ Glycopyrronium bromide equilibrates four to five times faster with the $M_{3}$ receptor than does tiotropium bromide and aclidinium bromide. ${ }^{8,11}$ This more rapid equilibration of glycopyrronium bromide with the $\mathrm{M}_{3}$ receptor is assumed to underlie its faster onset of action compared with that of tiotropium bromide, ${ }^{8}$ and probably also aclidinium bromide.

Early preclinical and clinical studies have suggested a very favorable safety profile for inhaled glycopyrronium bromide. Sechaud et $\mathrm{al}^{10}$ investigated the pharmacokinetics of glycopyrronium bromide following single and repeated once-daily inhalation in mild to moderate COPD patients, and reported that the pharmacokinetics of glycopyrronium bromide were consistent between doses and with limited systemic accumulation at steady state after repeated oncedaily inhalation. The overall incidence of adverse events was similar in patients treated with glycopyrronium bromide and placebo, apart from a higher frequency of dry mouth in the groups treated with glycopyrronium bromide. No serious adverse events were reported, and no clinically relevant effects were observed on vital signs, electrocardiography, or physical examinations. ${ }^{10}$

In a randomized, double-blind, placebo-controlled, parallel-group study, in which 257 patients with moderate to severe COPD were assigned to indacaterol plus glycopyrronium bromide, indacaterol, or placebo, Van de Maele et al ${ }^{12}$ investigated the change from baseline in 24-hour mean heart rate versus placebo. A total of 255 patients were 
included in the safety analysis, which showed no clinically significant differences between groups in the mean 24-hour heart rate or QTc interval, suggesting a cardiovascular safety profile of both long-acting bronchodilators similar to that of placebo.

The issue of inhaled anticholinergics and risk of major cardiovascular events has been much debated, and a metaanalysis of previously published studies has reported an increased risk of cardiovascular death, myocardial infarction, and stroke in COPD patients treated with inhaled anticholinergics, ${ }^{13}$ but conclusions regarding this point await the findings of ongoing prospective studies. In the clinical studies published so far, cardiac and vascular disorders have been reported at a similar frequency in the glycopyrronium bromide and placebo groups, although, as in other clinical trials of antimuscarinic agents in COPD, patients with any of a number of concomitant diseases, including symptomatic prostatic hyperplasia and narrow-angle glaucoma, were not eligible for inclusion.

\section{Clinical studies of glycopyrronium bromide \\ FEV}

Verkindre et $\mathrm{al}^{14}$ published one of the first double-blind, placebo-controlled trials of glycopyrronium bromide in patients with COPD. The study was conducted in 83 patients (78 patients completed the study) with stable moderate to severe COPD (mean post-bronchodilator $\mathrm{FEV}_{1}$ 53\% predicted). The patients were randomized to glycopyrronium bromide $12.5,25,50$ or $100 \mu \mathrm{g}$, placebo, or tiotropium bromide $18 \mu \mathrm{g}$ once daily (open-label active comparator) for 7 days. The primary endpoint was mean trough (23-24 hours following dosing) $\mathrm{FEV}_{1}$ on day 7. Mean trough $\mathrm{FEV}_{1}$ on days 1 and 7 was significantly higher with all active treatments versus placebo $(P<0.05)$. Glycopyrronium bromide $50 \mu \mathrm{g}$ and $100 \mu \mathrm{g}$ and tiotropium bromide showed clinically relevant improvements versus placebo on day 1 (differences 121, 135, and $112 \mathrm{~mL}$, respectively, $P<0.0001$ ) and day 7 (differences 131, 142, and $127 \mathrm{~mL}$, respectively, $P<0.0001)$. No clinically significant difference in improvements in $\mathrm{FEV}_{1}$ was observed between either dose of glycopyrronium bromide and tiotropium bromide, although a statistically significant difference in level of $\mathrm{FEV}_{1}$ in favor of glycopyrronium bromide was reported. Therefore, this study showed that glycopyrronium bromide once daily was well tolerated and demonstrated rapid and sustained 24-hour bronchodilatation, the latter being at least comparable with tiotropium bromide.
In a randomized, placebo-controlled trial, Vogelmeier et $\mathrm{al}^{15}$ studied the bronchodilator efficacy of two doses of glycopyrronium bromide $(100 \mu \mathrm{g}$ and $200 \mu \mathrm{g})$ versus placebo in patients with moderate to severe COPD (mean post-bronchodilator $\mathrm{FEV}_{1} 53 \%$ predicted). Enrolled patients were randomized to treatment with glycopyrronium bromide $100 \mu \mathrm{g}(\mathrm{n}=92)$, glycopyrronium bromide $200 \mu \mathrm{g}(\mathrm{n}=98)$, or placebo $(n=91)$ for 28 days. The primary objective was to evaluate safety, but efficacy measures were included as secondary objectives. Mean trough $\mathrm{FEV}_{1}$ was significantly higher in patients receiving glycopyrronium bromide compared with those receiving placebo. For glycopyrronium bromide $100 \mu \mathrm{g}$, the treatment differences from placebo were $131 \mathrm{~mL}$ and $161 \mathrm{~mL}$, respectively, on days 1 and 28 $(P<0.05)$; for glycopyrronium bromide $200 \mu \mathrm{g}$, the treatment differences were $146 \mathrm{~mL}$ and $151 \mathrm{~mL}$, respectively, on days 1 and $28(P<0.05)$. In line with this, peak $\mathrm{FEV}_{1}, \mathrm{FEV}_{1}$ at all time points up to 24 hours after dosing, and $\mathrm{FEV}_{1}$ area under the curve (AUC) from 5 minutes to 5 hours after dosing were also significantly higher for both doses of glycopyrronium bromide compared with placebo. Although this study did not include an active comparator, its reported findings support the bronchodilator efficacy of glycopyrronium bromide in patients with moderate to severe COPD.

In a small, randomized, double-blind, placebo-controlled, two-period crossover trial, Fogarty et $\mathrm{al}^{16}$ studied the bronchodilatory effects of glycopyrronium bromide versus placebo in 33 patients with moderate COPD (mean postbronchodilator $\mathrm{FEV}_{1} 70 \%$ predicted). Only subjects with at least a $5 \%$ increase in $\mathrm{FEV}_{1}$ following inhalation of ipratropium bromide were eligible for the study. Patients were randomized to receive glycopyrronium bromide $50 \mu \mathrm{g}$ once daily followed by placebo or vice versa for 14 days; the treatment periods were separated by a washout period of 7-14 days. The primary efficacy variable was the standardized FEV ${ }_{1}$ AUC between 0 and 24 hours after dosing on day 14 . The $\mathrm{FEV}_{1} \mathrm{AUC}_{0-24 \mathrm{~h}}$ values on day 14 were significantly higher for glycopyrronium bromide than for placebo $(P<0.001)$ with a least squares mean difference of $163 \mathrm{~mL}$ between glycopyrronium bromide and placebo. The FEV ${ }_{1}$ with glycopyrronium bromide was significantly higher $(P<0.001)$ than for placebo for all AUCs evaluated. On day 14 , significant treatment differences were found in mean $\mathrm{FEV}_{1} \mathrm{AUC}_{0-5 \mathrm{~h}}$ (difference $198 \mathrm{~mL}, P<0.001$ ), $\mathrm{FEV}_{1}$ $\mathrm{AUC}_{0-12 \mathrm{~h}}$ (difference $165 \mathrm{~mL}, P=0.001$ ), and $\mathrm{FEV}_{1} \mathrm{AUC}_{12-24 \mathrm{~h}}$ (difference $161 \mathrm{~mL}, P<0.001$ ) versus placebo. Furthermore, all primary analyses for trough $\mathrm{FEV}_{1}$ comparisons showed a clinically significant effect (predefined threshold exceeded, 
ie, $120 \mathrm{~mL}$ ) at the $5 \%$ level, except for the treatment least squares mean difference in trough value for glycopyrronium bromide on day $7(91 \mathrm{~mL})$. The mean difference in peak $\mathrm{FEV}_{1}$ values between glycopyrronium and placebo was $208 \mathrm{~mL}$ $(P<0.001)$ on day 14 and $173 \mathrm{~mL}(P=0.011)$ on day 7 , respectively. Therefore, this study supports the notion that glycopyrronium bromide provides significant and sustained 24-hour bronchodilatation in patients with COPD, similar to that provided by tiotropium bromide. ${ }^{17}$

In one of the largest published clinical trials of glycopyrronium bromide (The glycopyrronium bromide in CoPD airways clinical study 1 [GLOW1]), D’Urzu et al ${ }^{18}$ randomized patients with stable moderate to severe COPD (mean post-bronchodilator $\mathrm{FEV}_{1} 54 \%$ predicted) to either glycopyrronium bromide $50 \mu \mathrm{g}$ once daily $(\mathrm{n}=552)$ or placebo $(n=270)$ for 26 weeks. Patients were not eligible for the study if they were participating in a supervised pulmonary rehabilitation program. The primary outcome measure was trough $\mathrm{FEV}_{1}$ at week 12. Least squares mean trough $\mathrm{FEV}_{1}$ at week 12 was significantly higher in patients receiving glycopyrronium bromide $(1.41 \mathrm{~L})$ versus placebo $(1.30 \mathrm{~L})$, with a treatment difference of $108 \pm 15 \mathrm{~mL}(P<0.001)$. Significant improvements in trough $\mathrm{FEV}_{1}$ were observed at the end of day 1 and sustained through week $26 . \mathrm{FEV}_{1}$ was significantly improved in the glycopyrronium bromide group versus the placebo group throughout a 24-hour period on day 1 , at weeks 12 and 26, and at all other scheduled visits and time points.

In the GLOW 2 study, Kerwin et a ${ }^{19}$ randomized patients with moderate to severe $\mathrm{COPD}$ (mean $\mathrm{FEV}_{1} 56 \%$ predicted) to either glycopyrronium bromide $50 \mu \mathrm{g}$ once daily $(\mathrm{n}=525)$, open-label tiotropium $18 \mu \mathrm{g}$ once daily $(\mathrm{n}=267)$, or placebo $(n=268)$ for 52 weeks. The primary outcome measure was trough $\mathrm{FEV}_{1}$ at week 12. Least squares mean trough $\mathrm{FEV}_{1}$ at week 12 was significantly higher in patients receiving glycopyrronium bromide and tiotropium compared with that in patients receiving placebo, with a treatment difference of $97 \mathrm{~mL}(P<0.001)$ and $83 \mathrm{~mL}(P<0.001)$, respectively. Furthermore, trough $\mathrm{FEV}_{1}$ at weeks 26 and 52 was significantly higher for patients treated with glycopyrronium bromide versus placebo and comparable with tiotropium. At these time points, the treatment difference, compared with placebo, in favor of glycopyrronium bromide, was $134 \mathrm{~mL}$ and $108 \mathrm{~mL}$, respectively $(P<0.001)$, while the difference in favor of tiotropium was $84 \mathrm{~mL}$ and $89 \mathrm{~mL}$, respectively $(P<0.001)$. On day 1 , the least squares mean $\mathrm{FEV}_{1}$ treatment difference for glycopyrronium bromide/ placebo and tiotropium bromide/placebo was $87 \mathrm{~mL}$ and
$45 \mathrm{~mL}$ at 5 minutes, respectively, and $143 \mathrm{~mL}$ and $78 \mathrm{~mL}$ at 15 minutes, respectively $(P<0.001)$. The latter finding further supports the notion that glycopyrronium bromide has a faster onset of action than other inhaled antimuscarinic agents, including tiotropium bromide.

\section{Hyperinflation and exercise capacity}

Similar to the studies of indacaterol and tiotropium by O'Donnell et $\mathrm{al}^{20,21}$ and a study of aclidinium bromide by Maltais et al, ${ }^{22}$ a study by D'Urzu et a ${ }^{18}$ revealed a significant treatment difference in inspiratory capacity. The inspiratory capacity was significantly higher in patients receiving glycopyrronium bromide than in those receiving placebo at all time points on day 1 and at weeks 12 and 26 (all $P<0.001$ ). The glycopyrronium bromide/placebo difference for inspiratory capacity by the end of day 1 , week 12 , and week 26 was $104 \mathrm{~mL}, 97 \mathrm{~mL}$, and $113 \mathrm{~mL}$, respectively (all $P<0.001)$. These findings suggest that glycopyrronium bromide, like other long-acting bronchodilators, has a beneficial effect on dynamic hyperinflation in patients with COPD. In line with this, the GLOW2 trial ${ }^{19}$ also revealed a significantly higher inspiratory capacity in the glycopyrronium bromide group than in the placebo group, but comparable with that in the tiotropium group.

In the GLOW3 trial, Beeh et $\mathrm{a}^{23}$ evaluated the effect of once-daily glycopyrronium bromide on exercise tolerance in patients with moderate to severe COPD (mean postbronchodilator $\mathrm{FEV}_{1} 57 \%$ predicted). A total of 108 patients were randomized to glycopyrronium bromide $50 \mu \mathrm{g}$ once daily followed by placebo or vice versa for 3 weeks, with a 14-day washout period. The primary outcome measure was the effect of glycopyrronium bromide versus placebo on exercise tolerance after 3 weeks of treatment. Exercise tolerance was measured by exercise endurance time during a submaximal constant-load cycle ergometry test. Secondary outcome measures included inspiratory capacity at isotime (refers to the last time point in the ergometry test at which each patient had a valid test result for both treatment periods) and inspiratory capacity at rest. Treatment with glycopyrronium bromide was significantly superior to placebo with respect to exercise endurance time at 3 weeks, and the least squares mean difference between treatment groups was 89 seconds $(P<0.001)$. At the same time point, glycopyrronium bromide also produced statistically significant treatment differences in inspiratory capacity at isotime $(P<0.001)$ and inspiratory capacity at rest $(P<0.05)$. Therefore, the effect of glycopyrronium bromide on exercise tolerance in patients with COPD 
appears to be comparable with that of other long-acting bronchodilators. $^{20-22,24}$

\section{Health status, symptom relief, and use of rescue medication}

During the 28-day treatment period in the study by Vogelmeier et al, ${ }^{15}$ patients receiving either dose of glycopyrronium bromide (100 $\mu \mathrm{g}$ or $200 \mu \mathrm{g}$ once daily) used significantly less rescue medication than patients in the placebo group $(P<0.05)$; the change from baseline in the number of puffs of rescue medication was -0.55 and -0.26 , respectively, in groups treated with glycopyrronium bromide $100 \mu \mathrm{g}$ and $200 \mu \mathrm{g}$ versus +0.51 in the placebo group. In keeping with this, the GLOW1 study ${ }^{18}$ showed that use of rescue medication was significantly lower in patients receiving glycopyrronium bromide than in those on placebo $(P=0.005)$, with a between-group difference of 0.46 puffs per day. A reduction in the use of rescue medication was also observed in the GLOW2 trial by Kerwin et al, ${ }^{19}$ with a between-group treatment difference of 0.37 puffs per day $(P=0.039)$ and 0.63 puffs per day $(P=0.003)$, respectively, in the glycopyrronium bromide and tiotropium groups.

In the GLOW 1 study by D'Urzu et al, ${ }^{18}$ patients receiving glycopyrronium bromide had a significantly greater transition dyspnea index focal score at week 26 (1.84) compared with patients receiving placebo $(0.80)$. The observed treatment difference of 1.04 exceeded the minimal clinically important difference of one point. Furthermore, patients treated with glycopyrronium bromide were 1.7-fold more likely to have at least a one-point improvement in transition dyspnea index focal score compared with those on placebo $(P=0.001)$. Furthermore, patients treated with glycopyrronium bromide had a significantly lower (ie, better) St George's Respiratory Questionnaire score at week 26 (39.50) than patients treated with placebo (42.31). The treatment difference was -2.81 , which was statistically significant, but did not reach the minimal clinically important difference of $\geq 4$ points. The percentage of patients achieving a $\geq 4$ point reduction in St George's Respiratory Questionnaire score was significantly greater with glycopyrronium bromide than with placebo (56.8\% and $46.3 \%$, respectively, odds ratio $1.58, P=0.006$ ). Similar findings with regard to transition dyspnea index focal score and St George's Respiratory Questionnaire score were reported from the GLOW2 trial, ${ }^{19}$ although the statistically significant treatment difference in transition dyspnea index focal score did not reach the minimal clinically important difference (glycopyrronium bromide versus placebo 0.81 and tiotropium versus placebo 0.94 , respectively).

\section{Exacerbations}

In the GLOW1 trial, ${ }^{18}$ acute exacerbations of COPD were in line with those in previously published studies ${ }^{25}$ being classified as of moderate severity if they required treatment with systemic corticosteroids or an antibiotic and severe if they also required hospitalization. A previous history of acute exacerbations of COPD was not an inclusion criterion ( $79 \%$ of the enrolled patients had no history of moderate or severe exacerbation in the year prior to screening). Time to first moderate or severe COPD exacerbation was a secondary outcome measure. During the 26 -week study period, ${ }^{18} 93$ of 532 patients (17.5\%) in the glycopyrronium bromide group had at least one moderate or severe COPD exacerbation, compared with 63 of 260 patients $(24.2 \%)$ in the placebo group. Glycopyrronium bromide significantly reduced the risk of COPD exacerbations in terms of time to first moderate or severe COPD exacerbation by $31 \%$ compared with placebo (hazards ratio [HR] 0.69, confidence interval [CI] $0.50-0.95, P=0.023)$. Furthermore, a significant reduction was also observed in the risk of a COPD exacerbation leading to hospitalization in the glycopyrronium bromide group versus placebo (HR 0.35, CI 0.14-0.86, $P=0.022$ ). A significant reduction was also observed in the percentage of hospitalizations due to an exacerbation of COPD $(1.7 \%$ and $4.2 \%$, respectively, odds ratio $0.34, P=0.024)$ with glycopyrronium bromide versus placebo.

In the GLOW2 trial, ${ }^{19}$ glycopyrronium significantly reduced the risk of exacerbations (defined as in the GLOW1 trial) in terms of time to first moderate or severe exacerbation by $34 \%$ compared with placebo (HR $0.66,95 \%$ CI $0.52-0.85$, $P=0.001$ ) over 52, thereby demonstrating results comparable with tiotropium, which provided a $39 \%$ risk reduction versus placebo (HR 0.61, 95\% CI 0.46-0.81, $P=0.001$ ). Further, a $35 \%$ reduction was observed in the rate of moderate to severe COPD exacerbations in the glycopyrronium group compared with that in the placebo $(0.54$ versus 0.80 per year, relative risk 0.66 , CI $0.50-0.87, P=0.003$ ).

\section{Conclusion}

Based on the available evidence, glycopyrronium bromide (NVA237) is a safe and well tolerated long-acting anticholinergic bronchodilator with a fast onset of action. In patients suffering from COPD, glycopyrronium bromide has clinically important effects on $\mathrm{FEV}_{1}$, use of relief medication, daytime dyspnea scores, and probably also on health status. Furthermore, treatment with glycopyrronium bromide improves exercise tolerance in patients with moderate to severe COPD, as assessed by exercise endurance time and 
inspiratory capacity, suggesting a beneficial effect on dynamic hyperinflation, comparable with that of other long-acting bronchodilators, including tiotropium bromide, indacaterol, and aclidinium bromide. Glycopyrronium bromide has been shown to reduce the rate of exacerbations in patients with moderate to severe COPD, but long-term controlled trials with exacerbation rate as the primary outcome variable have not been published yet. In conclusion, glycopyrronium bromide may have a potentially significant role in the future management of moderate to severe COPD.

\section{Disclosure}

CSU has served on advisory boards for Novartis.

\section{References}

1. Global Strategy for the Diagnosis, Management, and Prevention of Chronic Obstructive Pulmonary Disease. Global Initiative for Chronic Obstructive Lung Disease (GOLD) 2011. Available from: http://www. goldcopd.org. Accessed September 6, 2012.

2. Celli BR, MacNee W. ATS/ERS Task Force. Standards for the diagnosis and treatment of patients with COPD: a summary of the ATS/ERS position paper. Eur Respir J. 2004;23:932-946.

3. Niewohner DE. Clinical practice. Outpatients management of severe COPD. $N$ Engl J Med. 2010;362:1407-1416.

4. Ulrik CS. Efficacy of inhaled salmeterol in the management of smokers with chronic obstructive pulmonary disease: a single centre randomised, double blind, placebo controlled, cross-over study. Thorax. 1995;50: 750-754.

5. Beeh KM, Wagner F, Khindri S, Drollmann AF. The effect of indacaterol on dynamic lung hyperinflation and breathlessness in hyperinflated patients with COPD. COPD. 2011;8:340-345.

6. Barnes PJ. The role of anticholinergics in chronic obstructive pulmonary disease. Am J Med. 2004;117:24S-32S.

7. Hodder R. Tiotropium is superior to salmeterol in reducing frequency of exacerbations: but the effect of adding tiotropium to the combination of inhaled corticosteroid and long-acting $\beta 2$-agonist remains unclear. Evid Based Med. 2012;17:93-95.

8. Sykes DA, Dowling MR, Charlton SJ. Exploring the mechanism of agonist efficacy: a relationship between efficacy and agonist dissociation rate at the muscarinic M3 receptor. Mol Pharmacol. 2009;76:543-551.

9. Vogelmeier C, Banerji D. NVA237, a long-acting muscarinic antagonist, as an emerging therapy for chronic obstructive pulmonary disease. Ther Adv Respir Dis. 2011;5:163-173.
10. Sechaud R, Ranard D, Zhang-Auberson L, de la Motte S, Drollmann A, Kaiser G. Pharmacokinetics of multiple inhaled NVA237 doses in patients with chronic obstructive pulmonary disease (COPD). Int $J$ Clin Pharmacol Ther. 2012;50:118-128.

11. Vestbo J, Vogelmeier C, Creemers J, Faiques M, Ribera A, Gil EG. Onset of effect of aclidinium, a novel long-acting muscarinic antagonist, in patients with COPD. COPD. 2010;7:331-336.

12. Van de Maele B, Fabbri LM, Martin C, Horton R, Dolker M, Overend T. Cardiovascular safety of QVA149, a combination of indacaterol and NVA237, in COPD patients. COPD. 2010;7:418-427.

13. Singh S, Loke YK, Furberg CD. Inhaled anticholinergics and risk of major adverse cardiovascular events in patients with chronic obstructive pulmonary disease. A systematic review and meta-analysis. JAMA. 2008;300:1439-1450.

14. Verkindre C, Fukuchi Y, Flemale A, et al. Sustained 24-h efficacy of NVA237, a once-daily long-acting muscarinic antagonist, in COPD patients. Respir Med. 2010;104:1482-1489.

15. Vogelmeier C, Verkindre C, Cheung D, et al. Safety and tolerability of NVA237, a once-daily long-acting muscarinic antagonist, in COPD patients. Pulm Pharmacol Ther. 2010;23:438-444.

16. Fogarty C, Hattersley H, Di Scala L, Drollmann A. Bronchodilatory effects of NVA237, a once daily long-acting muscarinic antagonist, in COPD patients. Respir Med. 2011;105:337-342.

17. Casaburi R, Conoscenti CS. Lung function improvements with oncedaily tiotropium in chronic obstructive pulmonary disease. Am J Med. 2004;117:33S-40S.

18. D'Urzu A, Ferguson GT, van Noord JA, et al. Efficacy and safety of once-daily NVA237 in patients with moderate to severe COPD: the GLOW1 trial. Respir Res. 2011;12:156.

19. Kerwin E, Hebert J, Gallagher N, et al. Efficacy and safety of NVA237 versus placebo and tiotropium inpatients with moderate-to-severe COPD over 52 weeks: The GLOW2 study. Eur Respir J. 2012.

20. O'Donnell DE, Casaburi R, Vincken N, et al. Effect of indacaterol on exercise endurance time and lung hyperinflation in COPD. Respir Med. 2011;105:1030-1036.

21. O'Donnell DE, Fluge T, Gerken F, et al. Effects of tiotropium on lung hyperinflation, dyspnea and exercise tolerance in COPD. Eur Respir J. 2004:23:832-840

22. Maltais F, Celli B, Casaburi R, et al. Aclidinium bromide improves exercise endurance and lung hyperinflation in patients with moderate to severe COPD. Respir Med. 2011;105:580-587.

23. Beeh KM, Singh D, Di Scala L, Drollmann A. Once-daily NVA237 improves exercise tolerance from the first dose in patients with COPD: the GLOW3 trial. Int J COPD. 2012;7:503-513.

24. Casaburi R. Factors determining constant work rate exercise tolerance in COPD and their role in dictating the minimal clinically important difference in response to interventions. COPD. 2005;2:131-136.

25. Jonesi PW, Rennard SI, Agusti A, et al. Efficacy and safety of oncedaily aclidinium in chronic obstructive pulmonary disease. Respir Res. 2011;12:55.
International Journal of COPD

\section{Publish your work in this journal}

The International Journal of COPD is an international, peer-reviewed journal of therapeutics and pharmacology focusing on concise rapid reporting of clinical studies and reviews in COPD. Special focus is given to the pathophysiological processes underlying the disease, intervention programs, patient focused education, and self management protocols.

\section{Dovepress}

This journal is indexed on PubMed Central, MedLine and CAS. The manuscript management system is completely online and includes a very quick and fair peer-review system, which is all easy to use. Visit $\mathrm{http} / / / \mathrm{www}$. dovepress.com/testimonials.php to read real quotes from published authors. 